\title{
Qualitative Process Evaluation of a Social Support Educational Program for Youths
}

\author{
Mami Kasahara-Kiritani, Fumitaka Masuda, Ayaka Ishii \\ Light Ring (Nonprofit Organization), Tokyo, Japan \\ Email: lightring.kiritani@gmail.com
}

Received 11 February 2015; accepted 15 March 2015; published 23 March 2015

Copyright (C 2015 by authors and Scientific Research Publishing Inc.

This work is licensed under the Creative Commons Attribution International License (CC BY). http://creativecommons.org/licenses/by/4.0/

c) (†) Open Access

\begin{abstract}
We evaluated the development of a social support educational program on future supporters. The intervention trained youths in their 20s and 30s who are providing or will provide social support to mentally vulnerable youths. We conducted brief interviews with 69 participants, analyzing data through content analysis. Most participants found the program useful in terms of meeting new peers, gaining new techniques for supporting others, relaxing through meeting peers, and assuring their competence to support others. There were concepts that participants developed, but were not aware of until the program concluded. To accomplish its goals, more effective publicity is necessary.
\end{abstract}

\section{Keywords}

\section{Social Support, Task Shifting, Youth, Helper Theory}

\section{Introduction}

Suicide is a major problem in Japan and worldwide, because it is one of the three leading causes of death in young people [1] [2], and accounts for $7.3 \%$ of all deaths among 15 to 19 year olds in 2009, which is less than those killed in road traffic accidents $(11.6 \%)$, but more than those killed through violence (6.2\%), respiratory tract infections (5.4\%), tuberculosis (4.8\%), or HIV (2.3\%) [3]. According to the latest data, these figures are similar today [4]. Japan's high suicide rate has been gradually decreasing, but not amongst the country's youth. Suicide is the cause of death for approximately 50\% of 15 to 39 year olds in Japan [5] [6]. More than 70\% of youths suicide assumed to be suffering from mental disease [5]. This means that mental diseases may be the primary cause of suicide among Japanese youths.

The idea of task shifting might be useful [7], and this approach has been put into practice in the form of support programs in Japan. There are several mental health improvement programs that aim to prevent suicide in 
Japan [8]. Federation of Inochi No Denwa Inc. [9], for example, is an established counseling helpline available all over Japan, and "Kokoro mo mentesi you" [10] is a website aimed at helping youths with mental health problems. A main limitation of these programs however is that young people with mental health problems need to contact using their own initiative. Evidence shows that young people with mental health issues tend to avoid talking to outside support, partially because of the stigma attached to mental diseases [11] [12]. Instead, a previous study has demonstrated that youths with mental health issues prefer to talk to friends and/or family members [6]. Light Ring, a nonprofit organization founded in 2012 [13], aims to prevent mental health diseases among youths in Japan. Light Ring operates on the basis that empowering those close to a depressed youththeir supporters - as paraprofessionals is an effective method to prevent mental diseases, which is also based on helper theory [14].

In order to empower supporters, Light Ring organizes social-support educational programs. Here, social support is defined as the "availability of people on whom we can rely: people who let us know that they care about, value, and love us” [15]. Previous studies show that these supportive relationships help to facilitate positive adjustment, buffer against stressors and adversities, and counter both medical and psychiatric problems [16] [17]. The three types of support are emotional support, instrumental support and information support. Emotional support offers esteem, attachment and reassurance; instrumental support offers material goods and services; and information support offers advice, guidance and feedback [15]. Social support educational programs aim to provide emotional and information support toward two groups of people: potential supporters and existing supporters. Light Ring Time (LRT) is one such social support educational program run by Light Ring that uses mutual counseling and case methods.

This paper aims to explore to what extent LRT meets the needs of participants, as well as to search for any unexpected effects, in order to further improve the program by comparing actual outcomes to the program's goals. This research will contribute to the development of empowerment programs for youths in other countries than Japan.

\section{Methodology}

\subsection{Overview of Light Ring Time}

LRT is a three-hour course consisting of introduction, mutual counseling, active listening training and wrap up. Each module has its goals (see Table 1 for details). In the mutual counseling session, participants share their difficulties based on a theme provided by LRT staff. One example of a theme would be "What would you do if your depressed friend sent you an e-mail at two a.m.?” Participants discuss how they would react in such situations, what kind of words they would choose to talk to the person, etc. Discussions are recorded and used as a resource for promoting Light Ring's activities. During the active listening training sessions, participants learn seven listening skills (line of vision, posture, voice, back-channel feedback, repetition, summarizing and questioning) through role-play. Participants rotate between the roles of listener, speaker, and observer during the session. Every time one role-play finishes, the observer gives feedback to the other two roles. The degree of attain-

\section{Table 1. Module duration and contents of Light Ring Time.}

\begin{tabular}{|c|c|c|}
\hline Module title & Main topics covered/goals for each section & Time per module \\
\hline Introduction & $\begin{array}{l}\text { 1) Introduce trainers and participants to each other. } \\
\text { 2) Begin to create a comfortable and interactive learning environment. } \\
\text { 3) Provide an overview of Light Ring Time. }\end{array}$ & $30 \mathrm{~min}$ \\
\hline Mutual counseling & $\begin{array}{l}\text { 1) Offer the chance for supporters to practice encouraging their clients. } \\
\text { 2) Discuss strategies for supporting depressed individuals, such as taking good care of } \\
\text { themselves, keeping their distance or changing their mood. }\end{array}$ & $55 \mathrm{~min}$ \\
\hline Interval & & $10 \mathrm{~min}$ \\
\hline Active listening training & $\begin{array}{l}\text { 1) Introduce the concept of active listening to participants. } \\
\text { 2) Introduce the skill set for active listening. } \\
\text { 3) Involve participants in skill-building exercises related to active listening through } \\
\text { role-play. Participants play the listener, speaker and observer. }\end{array}$ & $45 \min$ \\
\hline Wrap up and conclusion & $\begin{array}{l}\text { 1) Address any issues that may have come up during the training but were not resolved. } \\
\text { Once those issues are covered, participants have an opportunity to evaluate the trainers } \\
\text { and the course. }\end{array}$ & $40 \mathrm{~min}$ \\
\hline
\end{tabular}


ment is checked using a list of listening skills (Table 2). Approximately 20 people participate in each LRT. The program is held every other month and is supervised by a coaching professional. Staffs of Light Ring advertise LRT through media advertisements (television programs), webpages, Twitter, Facebook, and e-mails sent to past participants.

\subsection{Study Population}

Participants who joined LRT were recruited through media advertisements, Twitter, and e-mails sent to past participants of LRT. To be eligible, participants had to be over 18 years old, fluent in Japanese and have participated in LRT. Although achieving saturation was not a criteria used to establish the sample size, saturation was

Table 2. List of listening skills.

\section{Line of vision}

Establishing eye contact.

Demonstrating a sincere attitude.

Not staring, but looking comfortingly.

Calming oneself and comforting with the eyes in difficult situations.

\section{Posture}

Avoiding fidgeting or other signs of nervousness.

Maintaining posture, ex) crossing the legs may give the impression of rudeness.

Leaning forward a little.

Creating an atmosphere that matches the speaker's tone and rhythm.

\section{Voice}

His/her voice is loud enough to reach the speaker.

Appropriate tone and speed of speech.

Using a silky, comforting voice.

Being aware of one's vocal volume while talking.

\section{Back-channel feedback}

Using listening sounds such as "Fu-un" and "He-."

With the listener's feedback, the speaker perceives that they are being listened to.

Nodding timely, without interrupting the flow.

Nodding appropriately, not monotonously.

\section{Repetition}

Repeating words the speaker used.

Confirming the speaker's point.

Through repetition, s/he helps the speaker to organize his/her thoughts and to realize his/her own feelings.

$\mathrm{S} /$ he gives respect to the words of speakers, ex) s/he does not change the wording used too often.

\section{Summarizing}

Talk simply about what s/he understood.

What s/he understood follows the speaker's intent.

His/her feedback contains his/her feelings.

$\mathrm{S} / \mathrm{he}$ starts the summary in a natural way.

\section{Questioning}

$\mathrm{S} /$ he does not interrupt the speaker in wording or timing when asking a question.

Timing question so that the speaker feels comfortable to continue.

Use both closed and open questions properly.

Questions are not egocentric. 
observed during analysis through the consistency and redundancy of information during the interviews [18]. Exclusion criteria, evaluated by a psychiatric social worker, were the presence of significant psychopathological symptoms that would make participation in the study potentially hazardous for the participant.

\subsection{Data Collection}

We followed the ethical guideline published by Japanese Association of Industrial Counseling [19]. The first author acted as the independent evaluator and did not participate in the intervention development or delivery. Data collection occurred between July 2012 and April 2014. Participants were informed about the purpose of the study and were asked to participate in post-program interviews. More details were sent via e-mail to those that agreed to participate. The e-mail included assurances that participation was voluntary, confidential, and that responses would not be linked to respondents' identities. Participants were informed that they could refuse or discontinue participation in the study any time. Informed consent was sought when the e-mail was returned. AI conducted semi-structured interviews either immediately after the program or a week later. Interviews were conducted where privacy was assured including a café. The questions were, "How many times have you participated in LRT?" “Are you supporting someone now?" "What did you expect to gain from this program?” "How satisfied are you with the program? Could you explain the reason?" and "Has anything changed since you participated in the program? If so, could you explain the change in detail?” Instead of tape-recording the interviews, the interviewer wrote detailed memos immediately after the interviews concluded. Questions were generated based on psychological measurements [20] [21]. Interviews took at most 90 min to complete. Although such situation never happened, AI had contacts with a professional counselor or other medical professionals in case of anything unexpected happened to the study participants during or after the interviews.

\subsection{Analysis Strategy}

Content analysis was utilized to interpret the data [22] and participants' reasons for enrolling in and perceived learning from LRT were extracted. Two researchers (MK and MF) developed mutually agreed coding strategies for each theme. Responses were coded individually by both interviewers and then reviewed jointly. Consensus on coding differences was reached through discussion. We adopted case studies to observe the relationships among the themes.

\section{Findings}

\subsection{Participants}

Out of 128 participants of LRT, 59 people declined to participate along the way. Narratives were collected from 69 participants. A total of 36 males (52.2\%) and 33 females (47.8\%) participated in this study. All participants were in their $20 \mathrm{~s}$ or $30 \mathrm{~s}$. Among the participants, 34 (49.3\%) were employed, 18 (26.1\%) were students, 8 (11.6\%) were counselors, 4 (5.8\%) were other and 5 (7.2\%) were unknown. Welfare-related workers, psychiatric counselors, lawyers, and nurses were categorized as counselors. All participants could communicate in Japanese. Participants who were currently supporting, who had supported before, or who were willing to support but had no particular experience in supporting others, were interviewed. Those who already had someone to support were supporting their boy/girlfriends or anyone that goes together.

\subsection{Purposes of Enrolling in Light Ring Time}

Purposes of joining LRT were reported to be meeting new peers, gaining new techniques for supporting others, relaxing through meeting peers, or assuring their competence to support others. Some said that they joined because they were interested in the organization itself. Most participants seemed that they had already registered for LRT before they joined LRT (no data), while at least one participant joined without registration.

Participants wished to meet new peers and gather information on where they might be able to meet more peers. Participants' defined a peer as someone with whom they could share their worries and talk about their experiences with for a long period.

Other than the hope of acquiring long-lasting friendships, participants expected to encounter one-time friendship at LRT. Participants expected to gain new techniques for supporting others, relax through meeting peers, 
and assure their competence to support others through discussions with those who have experience in these fields or strong interest in supporting others.

Participants who were interested in the organization itself were those who were looking for a place to work or were supervisors of Light Ring. Not everyone that was interested in Light Ring itself began work for the organization afterwards.

\subsection{Participants' Perceived Learning from Light Ring Time}

After joining LRT, participants felt they gained new techniques for supporting others, relaxed through meeting peers, assured their competence to support others, acquired new peers, reflected on their own condition, and gained self-confidence and increased motivation. Reflecting on their own conditions and assuring their competence to support others seemed to have a big impact on the participants, as indicated by the high frequency of the code. Participants reported that it was helpful to receive feedback, and to be told what they can do as well as what they need to learn.

\subsection{Case Studies}

Here we present two case studies to help illustrate the relationship among the concepts. We also show examples of the concepts extracted above.

H.E. (male in his 20s).

H.E. was supporting his girlfriend who had been depressed. He felt he was not competent enough to support her effectively because he lacked stability ("I need assistance because I also am easy to be emotionally dragged.") and he was not confident of his supporting technique ("I think I need to let her air out her feelings but I don't know how." "When she is so depressed that she doesn't say a word, I have no idea how I can communicate with her.”) His purposes of joining LRT were to gain new techniques for support, as well as to meet peers so that he could share his concerns with them. In LRT, he exchanged ideas with others and learned through counseling and active listening, as well as self-care. He started to distinguish being a supporter from simply being himself and engaging in daily activities.

S.S. (male in his 20s).

S.S. had been supporting depressed people through social network services and face-to-face meetings. When talking with his clients, he tried to be easy to talk to ("I say 'yahho-' ('hello' in spoken language in Japanese) often."), to share his painful experiences ("I also have experience of being bullied in school. You seem to be highly anxious, too. Are you okay?"), to rest enough when supporting others ("I do not talk to them [his clients] when I am not in good condition. If I do, then I am afraid I might accuse them. The frequency of interviews depends on my physical capacity and timing.") and to have the client engage as much as he/she could do. However, he felt that he might not have the answers his clients were searching for due to a lack of knowledge and/or common sense. Through his LRT participation, he gained confidence after receiving positive reactions from others at his age. Learning about self-caring techniques made him want to learn more about this field. Participation in the interviews also gave him the chance to reflect on his abilities and to confirm his competences.

\section{Discussion}

We qualitatively evaluated the development process of LRT in terms of participants' fulfillment as well as the extent to which the program's goals were achieved. We found that LRT fulfilled the majority of participants' objectives, whereas some goals of LRT were unmet. Among the extracted themes, gaining new techniques for supporting others, relaxing through meeting peers, reflecting on their own condition, increased motivation, and assuring their competence to support others were attained through the exchanging of ideas among participants during LRT. Reflecting on their own condition, gaining self-confidence, and increased motivation were concepts that participants did not notice but had been improved until after the program. Repeat attendees of LRT had the solitary aim to re-join the program in order to strengthen their motivation to keep up their supporting role. Receiving positive responses from peers may strengthen participants' motivation, as well as help participants gain self-confidence.

In accordance with Sarason et al.'s definition (1983), this study demonstrated that LRT provided emotional and informational social support to participants. In addition, participants seemed to have realistic expectations 
from social support educational programs, as the desired outcomes were almost identical to those gained. In light of the fact that less than one-third of community mental health needs are met [23], LRT possibly plays an important role in the field of public mental health work among youths. This finding would help those who are to start a new social support educational program in Japan in part because such a program can empower the nonexpert supporters of vulnerable people.

Most participants had heard of LRT before they joined the program; that was, they were existing supporters. In order to achieve LRT's goal of recruiting more supporters, those that have not yet shown an interest in supporting others should also be contacted and invited to participate as a means of empowerment. This will require improving upon the program's current marketing activities.

Non-expert participants are able to identify some, but not all, possible benefits of self-help groups. It may be important to increase their awareness of these outcomes during the program sessions in order to help participants better advertise Light Ring, as well as generate an atmosphere of social support, which would help to press forward task-shifting in Japan.

A potential limitation of this study is the small sample size and the results of this research may not be fully applicable to other times and locations. Although we carefully followed the ethical guideline published by Japanese Accosiation of Industrial Counseling, gaining an approval from an institutional Ethical Committee should have increased the credibility of this study. We described the data collection procedure of this study in detail so that readers can make sure about our ethical considerations. Participants might tend to focus more on contribution to the society through their actions than those who declined to participate in this research. This tendency might strengthen the evaluation of LRT in a positive direction. The precise mechanisms for strengthening one's motivation or self-confidence will need to be addressed by future research. Although more extensive qualitative research will need to be conducted in order to assess the impact of helper theory, in which Light Ring has both qualitative and quantitative methodology roots. We found that helper theory was at work given that participants continued to willingly support others. We should further improve LRT and assess its impact in the future in order to see the effect of task-shifting in the field of youth mental health in Japan. Our findings would also contribute to developing a new social support educational program in other areas of world.

\section{Acknowledgements}

We wish to thank Shuntaro Ando and Yojiro Miura for their help in preparing the manuscript.

\section{References}

[1] Nock, M.K., et al. (2008) Suicide and Suicidal Behavior. Epidemiologic Reviews, 30, 133-154. http://dx.doi.org/10.1093/epirev/mxn002

[2] Wasserman, D., Cheng, Q. and Jiang, G.-X. (2005) Global Suicide Rates among Young People Aged 15-19. World Psychiatry, 4, 114.

[3] Patton, G.C., et al. (2009) Global Patterns of Mortality in Young People: A Systematic Analysis of Population Health Data. Lancet, 374, 881-892. http://dx.doi.org/10.1016/S0140-6736(09)60741-8

[4] Institute for Health Metrics and Evaluation, University of Washington (2013) COD Visualization. http://vizhub.healthdata.org/cod

[5] The Cabinet Office, Government of Japan (2014) White Paper on Suicide Prevention Tokyo.

[6] Bureau of Social Welfare and Public Health, Tokyo Metropolitan Government (2006) A Survey of Current Living Conditions of Citizens in Tokyo. Tokyo.

[7] Van Ginneken, N., et al. (2013) Non-Specialist Health Worker Interventions for the Care of Mental, Neurological and Substance-Abuse Disorders in Low- and Middle-Income Countries. Cochrane Database of Systematic Reviews, 11, Article ID: CD009149. http://dx.doi.org/10.1002/14651858.CD009149.pub2

[8] The Cabinet Office, Government of Japan (2014) Suicide Prevention. http://www8.cao.go.jp/jisatsutaisaku/index.html

[9] Federation of Inochi No Denwa Inc. (2014) http://www.find-j.jp/index.html

[10] Ministry of Health, Labour and Welfare, Japan (2011) Kokoro mo mentesi you. http://www.mhlw.go.jp/kokoro/youth/index.html

[11] Schomerus, G., Matschinger, H. and Angermeyer, M.C. (2009) The Stigma of Psychiatric Treatment and Help-Seeking Intentions for Depression. European Archives of Psychiatry and Clinical Neuroscience, 259, 298-306. http://dx.doi.org/10.1007/s00406-009-0870-y 
[12] Brohan, E., Slade, M., Clement, S. and Thornicroft, G. (2010) Experiences of Mental Illness Stigma, Prejudice and Discrimination: A Review of Measures. BMC Health Services Research, 10, 80. http://dx.doi.org/10.1186/1472-6963-10-80

[13] Nonprofit Organization Light Ring. (2014) http://lightring.or.jp/

[14] Riessman, F. (1965) The “Helper” Therapy Principle. Social Work, 10, 27-32.

[15] Sarason, I.G., Levine, H.M., Basham, R.B. and Sarason, B.R. (1983) Assessing Social Support: The Social Support Questionnaire. Journal of Personality and Social Psychology, 44, 127-139. http://dx.doi.org/10.1037/0022-3514.44.1.127

[16] George, L.K., Blazer, D.G., Hughes, D.C. and Fowler, N. (1989) Social Support and the Outcome of Major Depression. British Journal of Psychiatry, 154, 478-485. http://dx.doi.org/10.1192/bjp.154.4.478

[17] Gottlieb, B.H. (1982) Mutual-Help Groups: Members' Views of Their Benefits and of Roles for Professionals. Prevention in Human Services, 1, 55-67. http://dx.doi.org/10.1300/J293v01n03_06

[18] Pope, C., Ziebland, S. and Mays, N. (2000) Analysing Qualitative Data. Vol. 320.

[19] Japanese Association of Industrial Counseling (2014) Ethical Guidelines for Researches [in Japanese]. http://www.jaic.jp/society/rule/research ethical guidelines.pdf

[20] Matsui, Y., Ed. (2001) Indicatio/Clinical Mental Health Scales [Kokoro no kenkou wo hakaru (tekiou/rinshou)]. Vol. 3, Saiensu-Sha Co., Ltd. Publishers, Tokyo.

[21] Yoshida, F. and Miyamoto, S., Eds. (2011) Scales on Ego/Communication/Values [Kojin karashakai he (jiko/taijinkankei/ kachikan)]. Vol. 5, Saiensu-Sha Co., Ltd. Publishers, Tokyo.

[22] Krippendorf, K. (1989) Content Analysis. Vol. 1, Oxford University Press, New York.

[23] Messias, E., Eaton, W., Nestadt, G., Bienvenu, O.J. and Samuels, J. (2007) Psychiatrists’ Ascertained Treatment Needs for Mental Disorders in a Population-Based Sample. Psychiatric Services, 58, 373-377. http://dx.doi.org/10.1176/ps.2007.58.3.373 